\title{
SOME FACTORS AFFECTING ORANGE FRUIT SPLITTING OF WASHINGTON NAVEL ORANGE UNDER KAFERELSHIKH CONDITIONS. \\ B- THE EFFECT OF CLIMATIC CONDITIONS AND FRUIT POSITION ON THE TREE CANOPY.
}

Somaia A. El-Sayed

Citrus division, Sakha Hort Res. St, Kafrelsheikh, Egypt.

\begin{abstract}
This study was carried out during 2010 and 2011 seasons on 14 years old Washington navel orange trees ( C sinensis L .) grown on two citrus rootstocks ( Volkamer lemon and Sour orange ) and spaced at $5 \times 5 \mathrm{~m}$ in private orchard at Kafrelshikh Governorate, to study the effect of the climatic conditions and fruit position on fruit splitting under Kafrelshikh Climatic conditions .

The obtained results showed that, the incidence of splitting starts lightly in September coincidence with maximum air temperature and relative humidity before and after this period followed by gradual increase of fruit maturity. Trees on both Volkamer lemon and Sour orange rootstocks gave a high percentage of splitting, reaching a maximum values in November and December. The highest percentage of fruit splitting was counted in the southern aspect and lower part than in upper part of tree canopy. Trees on Sour orange rootstock in both seasons recorded the highest percentage of splitting compared to those on Volkamer lemon.
\end{abstract}

\section{INTRODUCTION}

Splitting may start as early as in september, with most occurring in late october ( $\mathrm{Y}-$ Zhengwen et.al. 2002). Severity of splitting is variable; some years are worth than others. Splitting orange fruits are usually due to stress on the tree, usually a combination of fluctuation temperatures, humidity and other factors such as the used cultivars on the given rootstock and fruit position on the tree canopy. This study puts light on the influence of air temperatures, relative humidity and fruit position on the tree canopy in relation to fruit splitting of Washington Navel orange at Kafrelsheikh climatic conditions.

\section{MATERIALS AND METHODS}

The Present study was carried out at a private orchard at Kafrelshikh governorate during 2010 and 2011 seasons on 14 years old Washington Navel orange trees budded on two citrus rootstocks ie.,Volkamer lemon (C. volkamariana) and Sour Orange (C.aurantium). The trees are grown in clay soil and spaced at 5X5 meter in a randomized complete design with three replicates each of three trees. Mechanical and chemical analysis of the experimental soil was done as shown inTable (1).

Table (1): Mechanical and Chemical analysis of experimental field

\begin{tabular}{|c|c|c|c|c|c|c|c|c|c|c|c|c|c|c|}
\hline \multicolumn{4}{|c|}{ Mechanical } & \multicolumn{3}{|c|}{ Chemical } & \multicolumn{3}{|c|}{ Available \% } & \multicolumn{5}{|c|}{ DTPA extractable ppm } \\
\hline $\begin{array}{c}\text { Sand } \\
\%\end{array}$ & $\begin{array}{c}\text { Silt } \\
\%\end{array}$ & $\begin{array}{c}\text { Clay } \\
\%\end{array}$ & & & EC & & $\begin{array}{l}\mathbf{N} \\
\%\end{array}$ & $\begin{array}{l}\mathbf{P} \\
\%\end{array}$ & $\begin{array}{l}\mathbf{K} \\
\%\end{array}$ & $\begin{array}{l}\mathrm{Ca} \\
\%\end{array}$ & $\begin{array}{c}\mathrm{Mg} \\
\%\end{array}$ & $\begin{array}{c}\mathrm{Na} \\
\%\end{array}$ & $\begin{array}{c}\text { Fe } \\
\text { Ppm }\end{array}$ & $\underset{\text { Ppm }}{\mathbf{Z n}}$ \\
\hline 9.65 & 32.15 & 58.20 & Tay & 0.0 & 3.35 & 1.90 & 0.0018 & 0.0007 & 0.0237 & 0.001 & 0.0005 . & 0.0025 & 20.09 & 9.97 \\
\hline
\end{tabular}

The experimental trees have been subjected to similar fertilization, irrigation and pest control practices usually done in the same orchard. Air temperature and humidity were recorded according to daily weather observation of Sakha research station. These data are presented in Table (2). In this study, an attempt to divide tree canopy to three parts, upper, medium and lower, then fruit splitting was observed and the percentage of fruit splitting is counted for each part.

Statistical analysis was done as analysis of variance according to the method described by Snedecor and Cochran (1967). The least significant differences (LSD at 5\% level). F.Test was used to compare between means

\section{RESULTS AND DISCUSSION}

1- Splitting evidence of Washington Navel orange as affected by climatic conditions.

Data in Table (2 and 3) and figs (1 and 2) clear that climatic condition; particularly air temperature and relative humidity are effective in inducing fruit splitting of Washington navel orange variety. It showed that, the incidence of splitting starts slightly in September followed by a gradual increase reaching its maximum values in December, at the same time, relative humidity also gradually increases, reaching a maximum value in December. Also, it was clear that the susceptibility of fruit to splitting increases with advancing fruit maturity. Data in Table (3) showed that, when fruit splitting ranged from (19 to $26 \%$ on sour orange and 16 to $17 \%$ on Volkamer lemon) in september in both seasons respectively, meanwhile air temperature reached a maximum value of about 33.4 and $33.2^{\circ} \mathrm{C}$ and relative humidity also reached a Maximum Value of about 82.2 and $88 \%$ in both seasons. In November the percentage of splitting also showed higher value and the highest value was recorded in December in both seasons. These results agree with Alfaro Ibenz(1988) who found that fruit splitting in early and late oranges varieties occurred between September and November when air temperatures 


\section{Somaia A. El-Sayed}

reached $19.27^{\circ} \mathrm{C}$ and coincided with the periods of increased relative humidity in Cuba. Moreover Coit (1915) suggested that the regions which more prone to warm weather are more likely to induce fruit splitting. In the same line Reuther et al (1973) found that, Valencia, orange exposed to warmer climate during the rapid growth period, developed thinner rind with higher percentage of fruit splitting compared to those exposed to lower temperatures. As for the effect of relative humidity Rabe et al (1989) reported that citrus fruit grown in humid production regions develop thinner rinds than those grown in drier regions and are therefore more likely to split. On the other hand, the results cleared that, the fluctuated climatic condition particularly; air temperature and relative humidity can change the physical and physiological properties of fruit peel and also can modify the water balance of the splitted fruit. These results agree with those of Vercher et al., 1994 and Alexander 1983.

Table (2): Air temperature $\left({ }^{\circ} \mathrm{C}\right)$ and relative humidity (\%) at Sakha experimental station in 2010 and 2011 years.

\begin{tabular}{|c|c|c|c|c|c|c|}
\hline \multirow{3}{*}{ Months } & \multicolumn{3}{|c|}{ Air temperature $\left({ }^{\circ} \mathrm{C}\right)$} & \multicolumn{3}{|c|}{ Relative Humidity (\%) } \\
\hline & Max & Min & Mean & Am & Pm & Mean \\
\hline & \multicolumn{6}{|c|}{2010} \\
\hline Jan. & 21.5 & 7.8 & 14.65 & 83.5 & 55.5 & 69.5 \\
\hline Feb. & 24.5 & 9.4 & 16.95 & 84.2 & 55.7 & 69.95 \\
\hline Mar. & 24.3 & 10.0 & 17.15 & 76.3 & 44.0 & 60.15 \\
\hline Apr. & 28.2 & 11.0 & 19.6 & 96.0 & 40.7 & 68.35 \\
\hline May & 29.6 & 14.4 & 22.0 & 72.6 & 39.5 & 56.05 \\
\hline June & 33.5 & 14.3 & 23.9 & 79.2 & 43.5 & 61.35 \\
\hline July & 32.0 & 20.0 & 26.0 & 82.0 & 48.2 & 65.10 \\
\hline Aug. & 34.0 & 21.2 & 27.6 & 85.0 & 50.8 & 67.90 \\
\hline Seb. & 33.4 & 19.2 & 26.3 & 82.2 & 48.5 & 65.35 \\
\hline Oct. & 30.7 & 17.0 & 23.85 & 72.0 & 45.0 & 58.5 \\
\hline Nov. & 26.8 & 11.0 & 18.9 & 82.0 & 54.2 & 68.10 \\
\hline Dec. & 22.0 & 8.3 & 15.15 & 85.0 & 55.7 & 70.35 \\
\hline \multirow[t]{2}{*}{ Mean } & 26.33 & 13.63 & & 81.67 & 48.44 & \\
\hline & \multicolumn{6}{|c|}{2011} \\
\hline June & 29.3 & 5.8 & 18.55 & 84.2 & 54.0 & 69.1 \\
\hline Feb. & 23.4 & 7.4 & 15.40 & 87.0 & 54.0 & 70.5 \\
\hline Mar. & 21.8 & 6.7 & 14.25 & 76.3 & 49.5 & 62.9 \\
\hline Apr. & 26.5 & 10.0 & 18.25 & 85.0 & 47.7 & 66.35 \\
\hline May & 29.0 & 13.0 & 21.0 & 76.7 & 38.0 & 57.35 \\
\hline June & 31.8 & 17.2 & 24.5 & 82.5 & 46.5 & 64.5 \\
\hline July & 33.0 & 19.4 & 26.2 & 79.5 & 49.2 & 64.35 \\
\hline Aug. & 32.5 & 19.2 & 25.85 & 84.0 & 50.0 & 67.0 \\
\hline Sep. & 33.2 & 17.7 & 25.45 & 88.0 & 49.6 & 68.6 \\
\hline Oct & 28.0 & 14.0 & 21.0 & 82.0 & 48.0 & 65.0 \\
\hline Nov. & 24.0 & 10.5 & 17.25 & 86.7 & 53.0 & 69.85 \\
\hline Dec. & 20.19 & 6.44 & 13.32 & 86.0 & 61.13 & 73.57 \\
\hline Mean & 27.72 & 12.28 & & 83.16 & 50.05 & \\
\hline
\end{tabular}

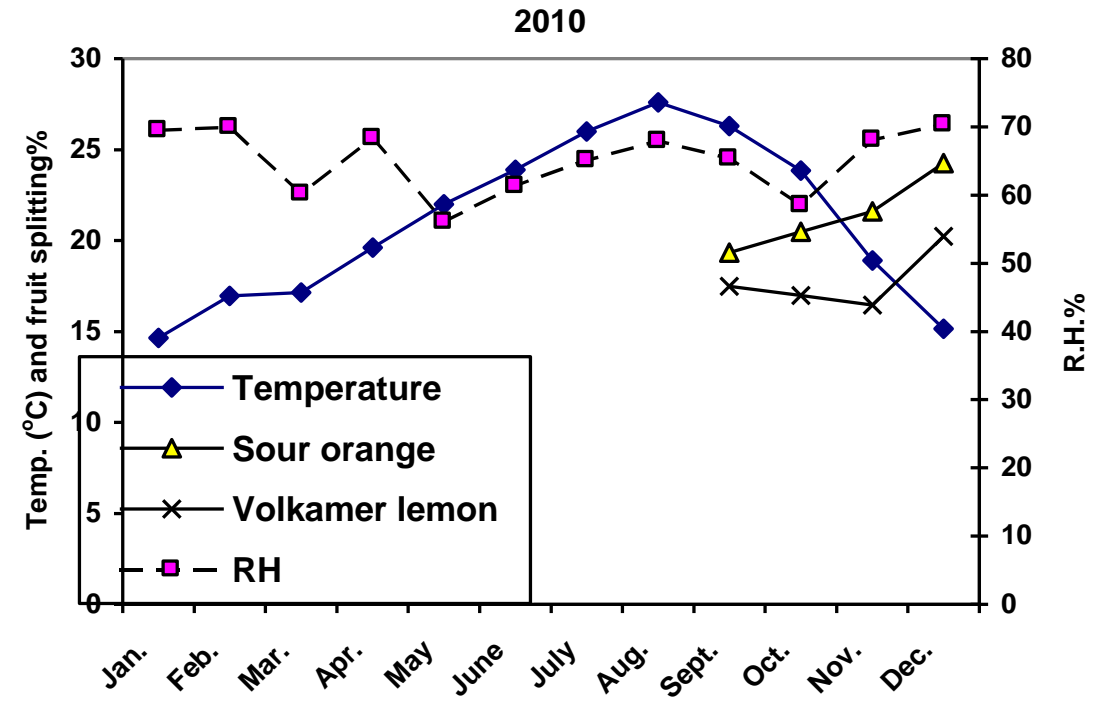

Fig.(1): Fruit splitting of Washington Navel Orange as affected by Air temperature and relative humidity under Kafr elsheikh climatic conditions in (2010) season. 


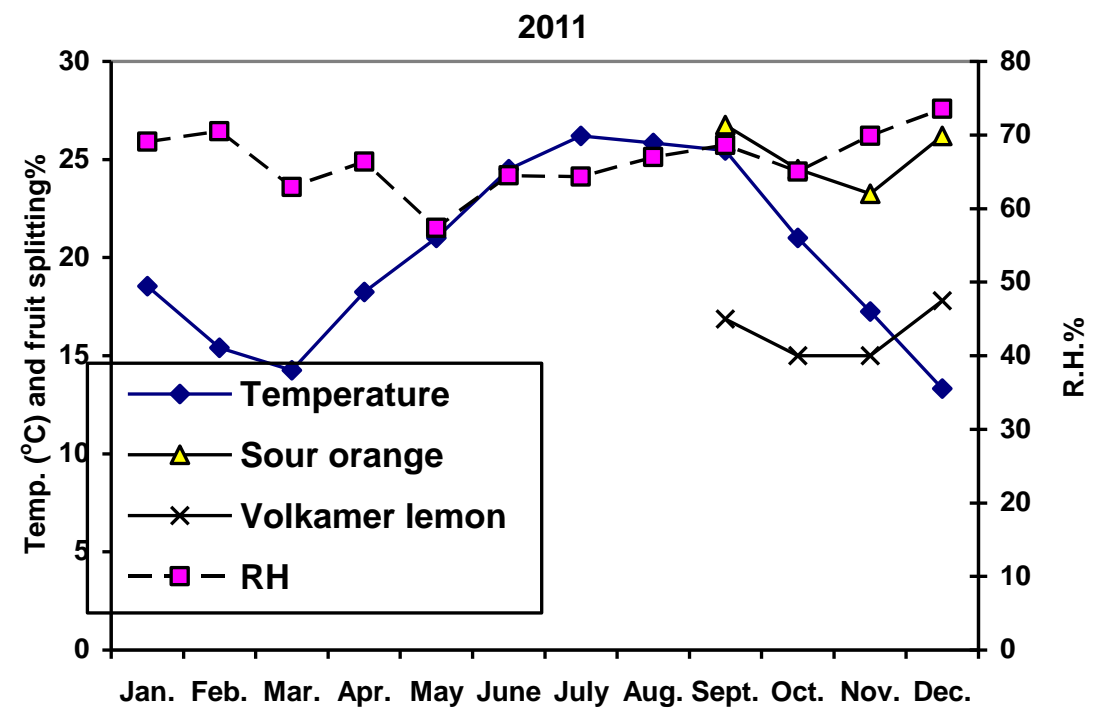

Fig.(2): Fruit splitting of Washington Navel Orange as affected by Air temperature and relative humidity under Kafr elsheikh climatic conditions in (2011)Season.

Data in Table (3) showed a clear influence of the used different rootstocks on fruit splitting. In this Respect, it was clear that Volkamer lemon rootstock recorded less percentage of fruit splitting when compared with Sour orange rootstock with significant differences between them in both seasons. This influence can be attributed to the vigorous effect of Volkamer lemon rootstock. This rootstock produced fruit with larger size and also thicker peel when compared to those on Sour orange rootstock. These results agree with those of Chen and Zhang (1995) they found that rootstock was shown to have an important effect on the percentage of cracking which reached $70.6 \%$ with Poncirus trifoliata rootstock, contrary to Yucheng (Citrus aurantium) rootstock who recorded only $5.5 \%$ of cracked fruit on it.

Table (3): Beginning of Splitting of Washington Navel orange on two different root stocks under climatic conditions of Kaferelsheik in 2010 and 2011 seasons.

\begin{tabular}{|c|c|c|c|c|c|}
\hline Rootstocks & Time & \multicolumn{4}{|c|}{ \% Fruit splitting 2010} \\
\hline \multicolumn{6}{|c|}{2010} \\
\hline Sour Orange & & 19.34 & 20.47 & 21.60 & 24.25 \\
\hline Volkamer lemon & & 17.48 & 16.00 & 16.45 & 20.23 \\
\hline F-test & & $*$ & $*$ & $*$ & $*$ \\
\hline \multicolumn{6}{|c|}{2011} \\
\hline Sour Orange & & 26.76 & 24.5 & 23.25 & 26.20 \\
\hline Volkamer lemon & & 16.68 & 15.0 & 15.00 & 17.80 \\
\hline F- test & & $*$ & $*$ & $*$ & $*$ \\
\hline
\end{tabular}

\section{2- Splitting as affected by fruit position on the tree :}

Data in Table (4) show that the southern side of the tree have fruits with higher percentage of splitting than on the other sides of the tree canopy in both rootstocks in the two seasons. These results agree with those of Garcia -Louis et al., (1994and 2001). Most likely, fruit position on the tree is behind the effect of air temperature and relative humidity around the fruit at different parts of the tree canopy as shown in tables $(2,4$ and figs 1,2).

Also, data in table (5) clear that, fruit position on tree canopy is important factor. The highest percentage of fruit splitting was recorded in the lower part of the tree at ( $1 \mathrm{~m}$ height), medium part of the tree at $(2 \mathrm{~m}$ height), and upper part of tree canopy at ( $3 \mathrm{~m}$ height), respectively in both seasons. As for the influence of rootstock, it was clear that Volkamer lemon rootstock recorded least value of fruit splitting in the low part when compared with Sour orange rootstock and the differences were significant between them ( table 5). In this connection, lower parts of the tree canopy exhibited significant increase in splitting more than higher parts. These results agree with those reported by Chikazumi (1989) and Augasti et al 2002, they reported that fruit position on tree canopy is effective in inducing fruit splitting and greeter splitting was observed in the interior than in exterior part of the tree canopy. The obtained results pay attention of the importance of tree pruning to open windows in interior and lower parts of the tree canopy. It could be concluded that pruning in winter service is not only important for improving fruit quality but also to minimize fruit splitting. 
Somaia A. El-Sayed

Table (4)- Effect of fruit position and distribution on \% fruit splitting of Washington Navel Orange grown under Kaferelsheikh climatic Conditions in 2010 and 2011 seasons.

\begin{tabular}{|c|c|c|c|c|c|}
\hline \multirow[b]{2}{*}{ Fruit position } & \multicolumn{5}{|c|}{$\%$ fruit splitting 2010} \\
\hline & East & West & South & North & Average \\
\hline Sour Orange & 4.04 & 7.20 & 9.69 & 4.01 & 6.02 \\
\hline Volkamer lemon & 3.19 & 5.30 & 9.43 & 3.29 & 5.31 \\
\hline F- test & $*$ & $*$ & $*$ & $*$ & NS \\
\hline \multicolumn{6}{|c|}{2011} \\
\hline Sour Orange & 4.83 & 6.87 & 16.13 & 3.09 & 7.73 \\
\hline Volkamer lemon & 4.61 & 3.93 & 14.75 & 4.11 & 6.85 \\
\hline F- test & $*$ & * & $*$ & $*$ & $*$ \\
\hline
\end{tabular}

* = significant NS = No significant

Table (5) - \% fruit splitting at different position of Washington Navel orange grown on two rootstocks under KafrElsheikh climatic conditions in 2010 and 2011 seasons.

\begin{tabular}{lcccc}
\hline Rootstocks & \multicolumn{2}{c}{ Fruit Splitting \% at different heights of tree canopy(m)) 2010 } \\
& Tree high & Lower part(1) & Medium part (2 m ) & Higher part (3m) \\
\hline Sour Orange & 12.65 & 7.10 & 5.94 \\
Volkamer lemon & 11.91 & 5.60 & 2.98 \\
F- test & $*$ & $*$ & $*$ \\
& & & & 6.035 \\
Sour Orange & 16,43 & & 8.523 & 5.015 \\
Volkamer lemon & 13.07 & 6.213 & $*$ \\
F- test & $*$ & $*$ & \\
\hline
\end{tabular}

\section{REFERENCES}

Alexander. D. M .(1983) . Some citrus species and varieties in Australia Cairo Adelaide

Alfaro Ibanez, D. (1988): Incidence of fruit splitting in orange . Centro - Agricola. 15 (14): 39-47.

Augasti, M., F.A Martinez and C. Mesejo,. (2002). Physiological Citrus fruit quality and techniques of improvement. Agrocenia montivides. 6(2):1- 16.

Chen, Q.D and Zhang (1995). Study on the mechanism of fruit cracking of Yuhuanyou pummelo and its control . Journal - Fruit - Science . 12(2): 139-140.

Chikaizumi, S. (1989). Studies on splitting of Navel orange (Citrus sinensis Osbeck var Brasitiensis Tanaka) fruit. Ehime-University -34(1): 73-80

Coit, J. (1915). Citrus fruits. Macmillan, New York.

Garcia, L. (1994). Fruit splitting in "Nova" hybrid mandarin in relation to the anatomy of the fruit and fruit set treatments: Scientia- Horticulturse $.57(3): 215-231$.
Garcia, L. (2001). The anatomy of the fruit in relation to propensity of citrus species to split. Scientia hort. 87,33-52.

Rabe, E., W. Van der Walt, and S. Kleynhans. (1989). Factors influencing fruit splitting in Ellendale. Annu. Rept. S.A. Co-Op. Citrus Exchange Ltd., Nelspruit

Reuther, W., E. M. Nauer, and L. Summers. (1973). Effects of seasonal temperature regimes on development and maturation of citrus fruit. Proc. Intl. Citricult. 3:63-71.

Vercher, R. and V. Almela. (1994). Rind structure epicutlar wax morphology Water pereability of Forttune Mandarin fruits affected by peel pitting. Ann, Bot . 74: 181-5.

Ye- Zhengwen and Z.K. Zhou. (2002). The fruit cracking rules of Navel orange varieties Such as Pengena and the effect of gibbrelic preventing fruits from Cracking. Acta. Hort, (4): 52-57.

\footnotetext{
بعض العوامل المؤثزه على تثقق ثمار البرتقال ابوسره صنف واشنطن تحت ظروف كفر الشيخ

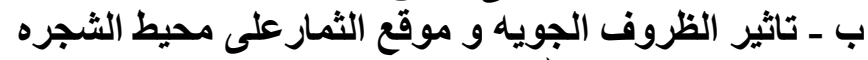
سميه احمد السيد عبد الله قسم الموالح - محطة بحوث البيد الثاتين بسخا_ كفر الشيخ - مصر

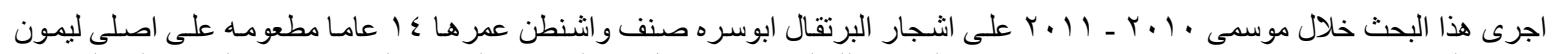

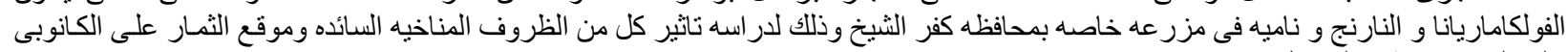

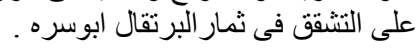

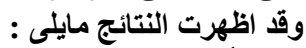

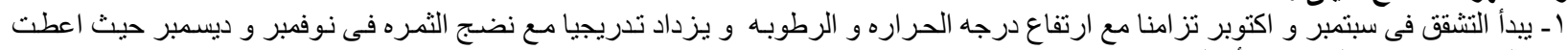

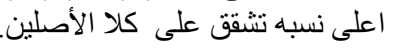

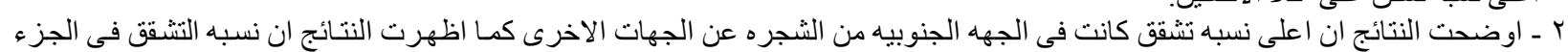

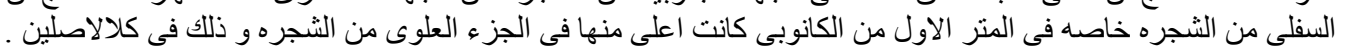

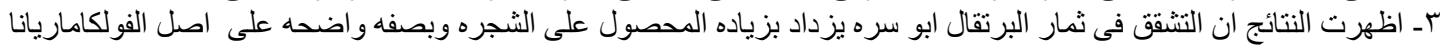

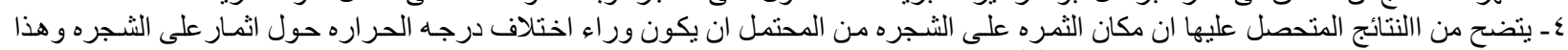
يؤكد أهميه التقليم لتحسين الاضاءة فى الداخل و ألأجز اء المنخفضه من الثجره و كذلك انلك تقليل نسبه التشقق فى الثمار.
} 